\title{
Polysilazane Precursor Used for Formation of Oxidized Insulator
}

\author{
Y. Urabe and T. Sameshima \\ Tokyo University of agriculture and Technology, Koganei, Tokyo 184-8588, Japan
}

Keywords: Polysilazane, $\mathrm{SiO}_{2}$ films, Insulator, High pressure $\mathrm{H}_{2} \mathrm{O}$ vapor heat

\begin{abstract}
We report $\mathrm{SiO}_{2}$ film formation using Polysilazane precursor treated with remote oxygen plasma and high pressure $\mathrm{H}_{2} \mathrm{O}$ vapor heating. Polysilazane precursor films with a thickness of $130 \mathrm{~nm}$ were formed on silicon substrates by spin coating method. They were annealed at $350^{\circ} \mathrm{C}$ in remote oxygen plasma at a pressure of $2.0 \times 10^{-2} \mathrm{~Pa}$ and a $13.56 \times 10^{6} \mathrm{~Hz}$ radio frequency power of $300 \mathrm{~W}$ for $3 \mathrm{~h}$ followed by $1.3 \times 10^{6} \mathrm{~Pa}-\mathrm{H}_{2} \mathrm{O}$ vapor at $260^{\circ} \mathrm{C}$ for $3 \mathrm{~h}$. Polysilazane films were entirely oxidized by high pressure $\mathrm{H}_{2} \mathrm{O}$ vapor heat treatment, and the density of Si-H bonding in Polysilazane films was effectively removed by the combination of high pressure $\mathrm{H}_{2} \mathrm{O}$ vapor heat treatment with remote oxygen plasma treatment. While MOS capacitors fabricated only by high pressure $\mathrm{H}_{2} \mathrm{O}$ vapor heat treatment had a high fixed oxide charge density of $2.3 \times 10^{12} \mathrm{~cm}^{-2}$ and a density of interface trap of $5.4 \times 10^{11} \mathrm{~cm}^{-2} \mathrm{eV}^{-1}$, remote oxygen plasma treatment followed by high pressure $\mathrm{H}_{2} \mathrm{O}$ vapor heat treatment was reduce them to $1.6 \times 10^{11} \mathrm{~cm}^{-2}, 4.6 \times 10^{10} \mathrm{~cm}^{-2} \mathrm{eV}^{-1}$, respectively. The combination of high pressure $\mathrm{H}_{2} \mathrm{O}$ vapor heat treatment with remote oxygen plasma treatment was effective to form $\mathrm{SiO}_{2}$ film using Polysilazane precursor.
\end{abstract}

\section{Introduction}

The formation of good quality of $\mathrm{SiO}_{2}$ films and $\mathrm{SiO}_{2} / \mathrm{Si}$ interface at low temperatures is important for device fabrication. We have reported that improvement in $\mathrm{SiO}_{2}$ film and $\mathrm{SiO}_{2} / \mathrm{Si}$ interface was achieved by high pressure $\mathrm{H}_{2} \mathrm{O}$ vapor heat treatment [1-2]. Polysilazane precursor have a possibility of gate insulator formation at low temperature because $\mathrm{SiO}_{2}$ film was fabricated by annealing at $450^{\circ} \mathrm{C}$ in air. In this study, we report $\mathrm{SiO}_{2}$ films formation using Polysilazane precursor treated with remote oxygen plasma and high pressure $\mathrm{H}_{2} \mathrm{O}$ vapor heating. Structural properties of $\mathrm{SiO}_{2}$ films are reported with analysis using Fourier transform infrared spectrometry (FTIR). Electrical properties of $\mathrm{SiO}_{2}$ films and $\mathrm{SiO}_{2} / \mathrm{Si}$ interface are also reported using $\mathrm{C}-\mathrm{V}$ measurement. We show a possibility of $\mathrm{SiO}_{2}$ films with good electrical properties for gate insulator using the present method.

\section{Experimental}

$\mathrm{SiO}_{2}$ films with a thickness of $130 \mathrm{~nm}$ were formed by spin coating method on P-type single crystalline silicon substrates. Remote oxygen plasma treatment was carried out with a flow of gases of Oxygen $\left(\mathrm{O}_{2}\right) 2 \mathrm{sccm}$ at a pressure of $1.0 \times 10^{-2} \mathrm{~Pa}$ and $13.56 \mathrm{MHz}$ radio frequency (RF) power of $300 \mathrm{~W}$ for $3 \mathrm{~h}$ with the temperature of $130^{\circ} \mathrm{C}, 260^{\circ} \mathrm{C}, 350^{\circ} \mathrm{C}$, respectively. The samples 
were subsequently heated at $260^{\circ} \mathrm{C}$ with $1.3 \times 10^{6} \mathrm{~Pa}-\mathrm{H}_{2} \mathrm{O}$ vapor for $3 \mathrm{~h}$. Optical absorption spectra of $\mathrm{SiO}_{2}$ films were measured using Fourier transform infrared spectrometry (FTIR) to investigate absorption ratio of $\mathrm{Si}-\mathrm{O}, \mathrm{Si}-\mathrm{H}$ and $\mathrm{Si}-\mathrm{O}-\mathrm{H}$ bondings. In order to investigate the electrical properties, Metal-Oxide-Semiconductor (MOS) capacitors were fabricated. Aluminum electrodes were formed on the $\mathrm{SiO}_{2}$ films with the area of $0.01 \mathrm{~cm}^{2}$ just after remote oxygen plasma treatment. The sample was subsequently heated at $260^{\circ} \mathrm{C}$ with $1.3 \times 10^{6} \mathrm{~Pa}-\mathrm{H}_{2} \mathrm{O}$ vapor for 3h. Capacitance responses at a frequency of $1 \mathrm{MHz}$ were measured.

\section{Results and Discussion}

Figure 1 shows optical absorption spectra measured for samples of Polysilazane precursor film as-spin coated (1), remote oxygen plasma treatment at $350^{\circ} \mathrm{C}(2)$, remote oxygen plasma treatment at $350^{\circ} \mathrm{C}$ followed by high pressure $\mathrm{H}_{2} \mathrm{O}$ vapor heat treatment (3). We focused on optical absorption peak corresponding to the Si-O vibration mode around $1080 \mathrm{~cm}^{-1}$, the $\mathrm{Si}-\mathrm{H}$ vibration mode around $2300 \mathrm{~cm}^{-1}$ and the Si-O-H vibration mode around 3500 $\mathrm{cm}^{-1}$. The arrows indicate those wave numbers. Optical absorption peaks corresponding to the Si-N vibration mode around $875 \mathrm{~cm}^{-1}$ and the $\mathrm{N}-\mathrm{H}$ vibration mode around $1175 \mathrm{~cm}^{-1}$ were observed in the spectrum of as-spin coated [10]. These are the composition of Polysilazane precursor. The intensities of Si-N and N-H peak were reduced by remote oxygen plasma treatment. On the other hand, the intensity of Si-O peak

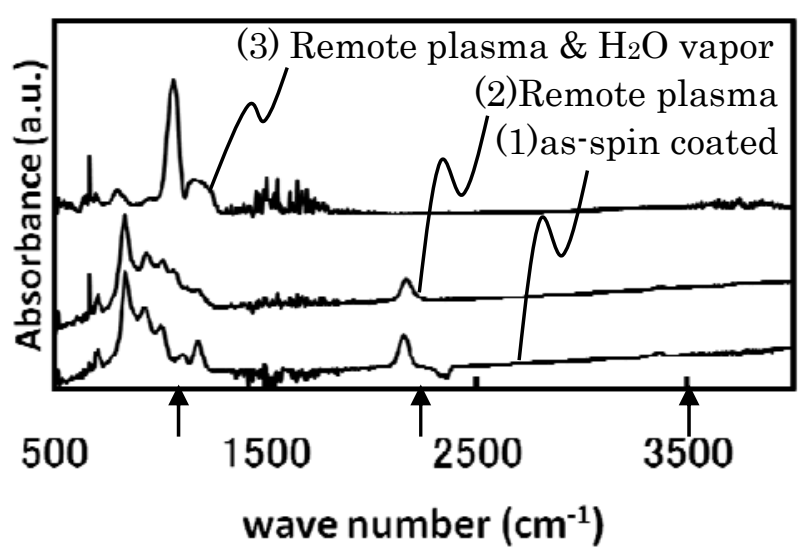

Fig.1: optical absorption spectra measured by FTIR for as-spin coated (1), remote oxygen plasma treatment at $350^{\circ} \mathrm{C}$ with the $\mathrm{RF}$ power of $300 \mathrm{~W}$ for $3 \mathrm{~h}(2)$, remote oxygen plasma treatment at $350^{\circ} \mathrm{C}$ with the RF power of $300 \mathrm{~W}$ for $3 \mathrm{~h}$ followed by $1.3 \times 10^{6} \mathrm{~Pa}-\mathrm{H}_{2} \mathrm{O}$ vapor heat treatment at $260{ }^{\circ} \mathrm{C}$ for 3 h (3). The arrows indicate optical absorption peak corresponding to $\mathrm{Si}-\mathrm{O}\left(1080 \mathrm{~cm}^{-1}\right)$, Si-H $\left(2100 \mathrm{~cm}^{-1}\right)$ and Si-O-H $\left(3500 \mathrm{~cm}^{-1}\right)$ vibration mode.

was slightly increased by remote oxygen plasma treatment. This means that Polysilazane precursor films were slightly oxidized by remote oxygen plasma treatment. The intensities of $\mathrm{Si}-\mathrm{N}$ and $\mathrm{N}-\mathrm{H}$ peak were completely reduced, and the intensity of Si-O peak was markedly increased by high pressure $\mathrm{H}_{2} \mathrm{O}$ vapor heat treatment after remote oxygen plasma treatment and its line shape became similar to that of thermally grown $\mathrm{SiO}_{2}$ films. These results indicate that oxidization of Polysilazane precursor films were effectively achieved by high pressure $\mathrm{H}_{2} \mathrm{O}$ vapor heat treatment. The intensity of $\mathrm{Si}-\mathrm{H}$ peak was reduced by remote oxygen plasma treatment, and it was completely reduced by high pressure $\mathrm{H}_{2} \mathrm{O}$ vapor heat treatment. Hydrogen was effectively removed during those oxidation processes. Si-O-H peak was slightly increased by high pressure $\mathrm{H}_{2} \mathrm{O}$ vapor heat treatment. We estimated total absorbance of optical absorption peaks by integrating from 900 to $1300 \mathrm{~cm}^{-1}$ corresponding to Si-O bonding, from 2100 to $2500 \mathrm{~cm}^{-1}$ corresponding to Si-H bonding and from 2900 to $3900 \mathrm{~cm}^{-1}$ corresponding to Si-O-H bonding.

Figure 2 shows total absorbance of optical absorption peaks corresponding to Si-O bonding (a), Si-H bonding (b) and Si-O-H bonding (c) as a function of heating temperature for remote oxygen plasma treatment. Total absorbance of optical absorption peaks corresponding to Si-O 
bondings treated by remote oxygen plasma treatment at $350^{\circ} \mathrm{C}$ followed by high pressure $\mathrm{H}_{2} \mathrm{O}$ vapor heat treatment was determined to be 100 . As-spin coated sample had an intensity of Si-O peak of 23 as shown in Figure.2 (a). Polysilazane intrinsically has no oxygen atoms. There is a possibility of that the total absorbance included optical absorption due to Si-N bonding. The total absorbance of optical absorption peaks corresponding to $\mathrm{Si}-\mathrm{O}$ bonding was increased to 44.5 by remote oxygen plasma treatment at $350^{\circ} \mathrm{C}$. This means that oxygen radicals oxidized Polysilazane precursor. Moreover, it was markedly increased to 100 by remote oxygen plasma treatment $350{ }^{\circ} \mathrm{C}$ followed by high pressure $\mathrm{H}_{2} \mathrm{O}$ vapor heat treatment. This result indicates that high pressure $\mathrm{H}_{2} \mathrm{O}$ vapor heat treatment entirely oxidized Polysilazane precursor. As-spin coated sample had a total absorbance of optical absorption peaks corresponding to $\mathrm{Si}-\mathrm{H}$ bonding of 22 as shown in Fig.2 (b). It was reduced to 9.4 by remote oxygen plasma treatment at $350^{\circ} \mathrm{C}$, and markedly reduced to 0.07 by remote oxygen plasma treatment at $350^{\circ} \mathrm{C}$ followed by high pressure $\mathrm{H}_{2} \mathrm{O}$ vapor heat treatment. These results indicate that the $\mathrm{Si}-\mathrm{H}$ bondings in Polysilazane precursor was effectively removed by the combination of high pressure $\mathrm{H}_{2} \mathrm{O}$ vapor heat treatment with remote oxygen plasma treatment. As-spin coated sample had a total absorbance of optical absorption peaks corresponding to $\mathrm{Si}-\mathrm{O}-\mathrm{H}$ bonding of 2.8 as shown in Fig.2 (c). There was no oxygen atom in Polysilazane precursor and the total absorbance of optical absorption peaks corresponding to Si-O-H bonding was small. It was reduced to 1.1 by remote oxygen plasma treatment at $350^{\circ} \mathrm{C}$. This result indicates that remote oxygen plasma treatment did not induce the formation of $\mathrm{Si}-\mathrm{O}-\mathrm{H}$ bonding. As shown in Figure 2 (b) and (c), remote oxygen plasma treatment effectively removed the $\mathrm{Si}-\mathrm{H}$ bondings

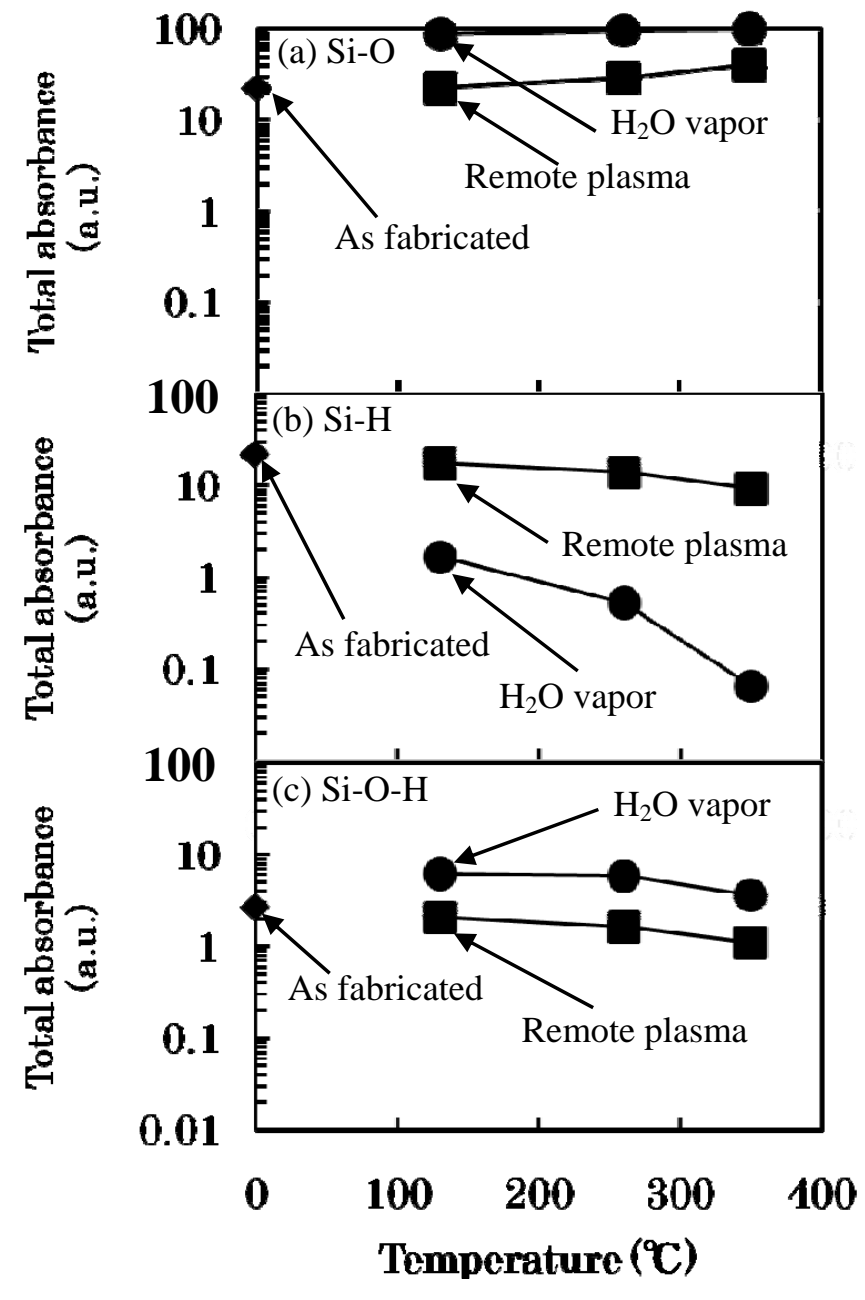

Fig.2: Total absorption corresponding to the intensity of Si-O peak (a), the intensity of Si-H peak (b) and the intensity of Si-O-H peak (c) as a function of heating temperature for remote oxygen plasma treatment. and did not form the Si-O-H bonding. On the other hand, the total absorbance of optical absorption peaks corresponding to Si-O-H bonding was increased to 3.7 by remote oxygen plasma treatment at $350^{\circ} \mathrm{C}$ followed by high pressure $\mathrm{H}_{2} \mathrm{O}$ vapor heat treatment. This result indicates that high pressure $\mathrm{H}_{2} \mathrm{O}$ vapor heat treatment induced hydroxyl to form the Si-O-H bondings in Polysilazane precursor.

Figure. 3 shows the fixed oxide charge and the interface trap states as a function of heating temperature for remote oxygen plasma treatment. We could not measure the capacitance responses for the sample fabricated by remote oxygen plasma treatement. We thought that it was not enough to oxidize Polysilazane precursor, because the sample had a small intensity of 
Si-O peak in FTIR optical absorption spectrum. The $\mathrm{SiO}_{2}$ films formed by high pressure $\mathrm{H}_{2} \mathrm{O}$ vapor heat treatment had a high fixed oxide charge of $2.3 \times 10^{12} \mathrm{~cm}^{-2}$ and a high interface trap states of $5.4 \times 10^{11} \mathrm{~cm}^{-2} \mathrm{eV}^{-1}$. Remote oxygen plasma treatment at $350{ }^{\circ} \mathrm{C}$ followed by high pressure $\mathrm{H}_{2} \mathrm{O}$ vapor heat treatment reduced them to $1.6 \times 10^{11} \mathrm{~cm}^{-2}$, $4.6 \times 10^{10} \mathrm{~cm}^{-2} \mathrm{eV}^{-1}$, respectively. Remote oxygen plasma treatment reduced the fixed oxide charge density and the interface trap states with increasing the heating temperature. These results indicate that remote oxygen plasma treatment at $350^{\circ} \mathrm{C}$ effectively reduced the defects of $\mathrm{SiO}_{2}$ films and $\mathrm{SiO}_{2} / \mathrm{Si}$ interface. It reduced $\mathrm{Si}-\mathrm{H}$ bondings as shown in Fig. 2(b). We thought that the low hydrogen content is required to form $\mathrm{SiO}_{2}$ films with low defect densities.

\section{Summary}

We investigated $\mathrm{SiO}_{2}$ films formation using Polysilazane precursor treated by

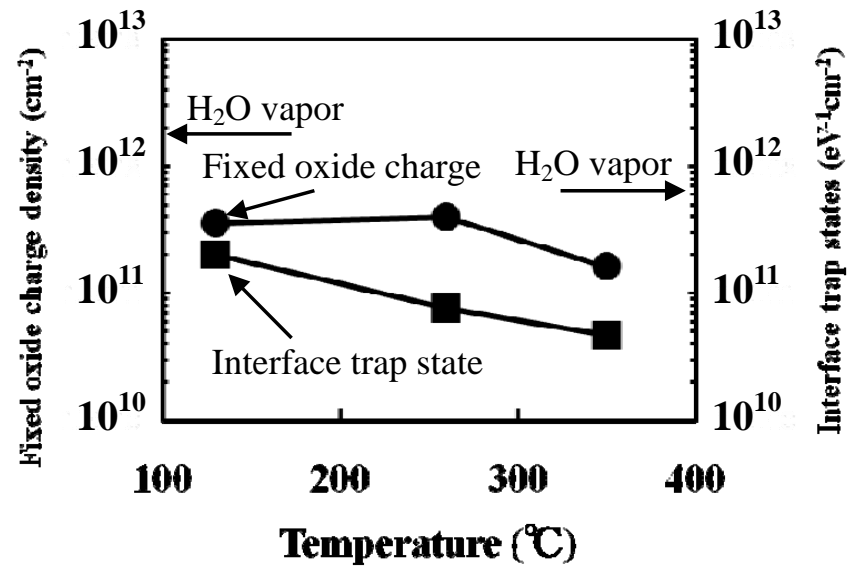

Fig.3: The fixed oxide charge density and the interface trap state as a function of heating temperature for remote oxygen plasma treatment. The arrows indicate that the fixed oxide charge density and the interface trap state for $\mathrm{SiO}_{2}$ films fabricated by $1.3 \times 10^{6} \quad \mathrm{~Pa}-\mathrm{H}_{2} \mathrm{O}$ vapor heat treatment at $260^{\circ} \mathrm{C}$ for $3 h$. remote oxygen plasma and high pressure $\mathrm{H}_{2} \mathrm{O}$ vapor heating. The total absorbance of optical absorption corresponding to $\mathrm{Si}-\mathrm{O}$ bonding after remote oxygen plasma treatment at $350^{\circ} \mathrm{C}$ followed by high pressure $\mathrm{H}_{2} \mathrm{O}$ vapor heat treatment was determined to be 100 . As-spin coated samples had a total absorbance of optical absorption corresponding to Si-O bonding of 22. It was increased to 44.5 by remote oxygen plasma treatment at $350^{\circ} \mathrm{C}$, and markedly increased to 100 by remote oxygen plasma treatment at $350^{\circ} \mathrm{C}$ followed by high pressure $\mathrm{H}_{2} \mathrm{O}$ vapor heat treatment. High pressure $\mathrm{H}_{2} \mathrm{O}$ vapor heat treatment entirely oxidized Polysilazane precursor. As-spin coated sample had a total absorbance of optical absorption corresponding to $\mathrm{Si}-\mathrm{H}$ bonding of 22. It was reduced to 9.4 by remote oxygen plasma treatment, and further reduced to 0.07 by remote oxygen plasma treatment at $350^{\circ} \mathrm{C}$ followed by high pressure $\mathrm{H}_{2} \mathrm{O}$ vapor heat treatment. The Si-H bonding in Polysilazane precursor was effectively removed by the combination of high pressure $\mathrm{H}_{2} \mathrm{O}$ vapor heat treatment with remote oxygen plasma treatment. On the other hand, the present combination treatment slightly increased the total absorbance of optical absorption corresponding to Si-O-H bonding from 2.8 to 3.7. While the MOS capacitor fabricated by high pressure $\mathrm{H}_{2} \mathrm{O}$ vapor heat treatment had a high fixed oxide charge density of $2.3 \times 10^{12} \mathrm{~cm}^{-2}$ and a density of interface trap of $5.4 \times 10^{11} \mathrm{~cm}^{-2} \mathrm{eV}^{-1}$, remote oxygen plasma treatment at $350^{\circ} \mathrm{C}$ followed by high pressure $\mathrm{H}_{2} \mathrm{O}$ vapor heat treatment reduced them to $1.6 \times 10^{11} \mathrm{~cm}^{-2}$ and $4.6 \times 10^{10} \mathrm{~cm}^{-2} \mathrm{eV}^{-1}$, respectively. From these results, the combination of high pressure $\mathrm{H}_{2} \mathrm{O}$ vapor heat treatment with remote oxygen plasma treatment improved electrical properties of $\mathrm{SiO}_{2}$ films and $\mathrm{SiO}_{2} / \mathrm{Si}$ interface.

\section{References}

[1] T. Sameshima, A. Kohno, M. Sekiya, M. Hara, and N. Sano, Appl. Phys. Lett. 648 (1994) 
[2] K. Sakamoto and T. Sameshima, Jpn. J. Appl. Phys. 39 (2000) pp.2492-2496

[3] T. Sameshima and M. Satoh, Jpn. J. Appl. Phys. 36 (1997) pp L687-L689

[4] K. Sakamoto and T. Sameshima, Jpn. J. Appl. Phys. 39 (2000) pp.2492-2496

[5] T. Sameshima, K. Sakamoto, T. Tsunoda and M. Saitoh, Jpn. J. Appl. Phys. 37, L1452, (2000)

[6] T. Sameshima, M. Satoh and K. Sakamoto, Thin Solid Films 335 (1998) 138

[7] H. Watakabe and T. Sameshima, Jpn. J. Appl. Phys. 41 L974 (2002)

[8] H. Watakabe and T. Sameshima, Proc in $1^{\text {st }}$ Thin Film Material \& Devices Meeting (Nara, 2004)

[9] T. Sameshima, M. Satoh and K. Sakamoto, K. Ozaki and K. Saitoh, Jpn. J. Appl. Phys. 37 (1998) 4254

[10] G. Lucovsky, J. Yang, S. S. Chao, J. E. Tyler, and W. Czubatyj, Phys. Rev. B 28 (1983) 3234 